\title{
A bola ao ritmo de fado e samba: 100 anos de relações luso-brasileiras no futebol 1913-2013
}

\author{
Juan Antonio Simón Sanjurjo*
}

\begin{abstract}
Resumo: Esta resenha refere-se ao livro "A bola ao ritmo de fado e samba: 100 anos de relações luso-brasileiras no futebol 1913-2013", coordenado pelos historiadores do esporte Francisco Pinheiro e Victor Andrade de Melo. O livro é uma coletânea de artigos em que 25 autores abordam a partir de múltiplas perspectivas o centenário das relações lusobrasileiras através do futebol e da evolução dessa relação centenária. Além disso, a obra oferece uma abordagem narrativa densa e pormenorizada, que agrega profundidade analítica e revelam novos aspectos sobre a relação através do futebol entre os dois países.
\end{abstract}

Palavras-chave: Futebol. Brasil. Portugal. Resenhas de livros

A bola ao ritmo de fado e samba: 100 anos de relações lusobrasileiras no futebol 1913-2013 es una obra coordinada por los historiadores del deporte Francisco Pinheiro y Victor Andrade de Melo. El 26 de junio de 1913 un grupo de jóvenes futbolistas portugueses pertenecientes a la Associaciação de Foot-ball de Lisboa deciden aceptar la invitación del Botafogo Foot-ball Club y tomar rumbo a Brasil para realizar una gira que les llevaría a visitar las ciudades de Rio de Janeiro y Sao Paulo. Aprovechando la conmemoración del centenario del inicio de las relaciones futbolísticas luso-brasileñas, los coordinadores del presente trabajo han logrado reunir un amplio número de textos con el objetivo de afrontar el estudio de las múltiples facetas que han rodeado las

"Centro de Estudios Olímpicos. Departamento de Ciencias de la Comunicación. Universidad Autónoma de Barcelona. Barcelona, España. E-mail: jasimonsanjurjo@hotmail.com 
experiencias compartidas entre ambos países a través del fútbol. Para poder alcanzar dicho fin, se ha contado con la participación de 25 autores, 12 portugueses y 13 brasileños, que han dado forma a los 22 capítulos que definen la estructura de esta obra.

El considerable aumento en los últimos años de la producción científica sobre la historia del deporte en Portugal y Brasil, así como el especial interés que se ha mostrado hacia el impacto que ha tenido en ambos países un fenómeno global como el fútbol, han permitido afianzar a nivel académico un ámbito de estudio que no había recibido la atención que se merecía desde las universidades y centros de investigación. Gran parte de la responsabilidad de esta transformación recae en grupos de investigación como el Grupo História e Desporto creado por el Instituto de História Contemporânea (IHC) de la Universidade Nova de Lisboa y el Centro de Estudos Interdisciplinares do Século XX de la Universidad de Coimbra-CEIS20 que coordina el propio Francisco Pinheiro, o el Sport: Laboratório de História do Esporte e do Lazer que lidera en Río de Janeiro Victor Andrade de Melo.

Pese a que no puede negarse la importancia de su contenido historiográfico, una de las principales virtudes de este libro es su claro perfil pluridisciplinar, lo que permite incorporar múltiples perspectivas de análisis ampliando sus diferentes enfoques y conclusiones. Reconocidos historiadores, sociólogos, filósofos, antropólogos, periodistas, lingüistas y escritores de ambos países han contribuido con sus textos a dar forma a una obra que como sus propios coordinadores señalan, busca conjugar el rigor científico con su compromiso por la divulgación sin caer en una "obra excesivamente intelectual" o "exageradamente popular-populista" (PINHEIRO; MELO, 2013, p. 19).

La multiplicidad de elementos que se tratan a lo largo de las más de cuatrocientas páginas de extensión de este libro abarcan aspectos como la utilización política del fútbol por Vargas y Salazar, la incorporación de la mujer en el mundo del fútbol, el fenómeno de la emigración de futbolistas, la violencia en el fútbol portugués y 
brasileño, el estudio de la estrecha relación entre cine y fútbol, o la comparación entre la terminología futbolística utilizada en los dos países. Al mismo tiempo, se diseccionan a lo largo de su contenido acontecimientos claves para poder entender la verdadera dimensión de la relación futbolística entre ambas sociedades, como fueron el enfrentamiento entre las respectivas selecciones nacionales en la Copa del Mundo de 1966, la final de la Copa Intercontinental de 1962 entre el Benfica liderado por Eusébio y el Santos de Pelé o el Mundialito de 1972, así como la influencia que han tenido clubes tan representativos como el Clube de Regatas Vasco da Gama o la Associaçao Académica de Coimbra.

La obra se inicia con un encuadre histórico sobre el origen y desarrollo del fútbol en ambas sociedades. Francisco Pinheiro y Mauricio Murad vuelven la vista al pasado en los dos primeros capítulos realizando un breve recorrido, pero imprescindible, por la historia del fútbol portugués y brasileño, incorporando sendas periodizaciones históricas que permiten concretar el marco estructural y cronológico de este ámbito de estudio y facilitar el desarrollo de futuras investigaciones. A continuación, en el capítulo 3, Francisco Pinheiro y Victor Andrade de Melo nos regalan un detallado análisis histórico del mencionado primer viaje a Brasil de un grupo de jóvenes jugadores portugueses de la Associaciação de Foot-ball de Lisboa en 1913, punto de inicio de las relaciones futbolistas entre ambos países. El texto presenta a lo largo de su contenido múltiples elementos de unión y discordia, de contagio e influencias y de pasión y desencuentros que han permitido configurar a lo largo de estos últimos cien años un específico elemento de estudio de las relaciones luso-brasileñas a través del fútbol. Un claro ejemplo de lo anterior son los capítulos 4 y 5 , en los que Sílvio Ricardo y Bruno Lacerda Abrahão afrontan el análisis del origen del Clube de Regatas Vasco da Gama, fundado por la colonia portuguesa de Rio de Janeiro, o el recorrido que realiza el sociólogo portugués João Nuno Coelho a través de los enfrentamientos de sus respectivas selecciones nacionales. En el primero de estos dos estudios, se subraya la transcendental evolución histórica del Vasco da Gama desde sus orígenes como club de remo

Movimento, Porto Alegre, v. 20, n. 3, p. 1243-1251, jul./set. de 2014. 
a su posterior integración en el espacio futbolístico brasileño, así como su determinante protagonismo en la lucha por la verdadera socialización y democratización de este deporte, apoyando la progresiva transformación de su tradicional perfil elitista con la incorporación en su plantilla de futbolistas de clase trabajadora y negros. La lucha contra la discriminación social y racial en el fútbol brasileño debe gran parte de sus éxitos al compromiso de sociedades como el Clube de Regatas Vasco da Gama. Respecto a la relación entre las selecciones nacionales, es interesante destacar cómo se analiza su evolución desde 1956 a partir de los primeros enfrentamientos y la creación del "mito da bola cuadrada", estrechamente relacionado con las supuestas carencias técnicas de los jugadores lusos; transitando por su posterior transformación con la llegada de los años sesenta y el punto de inflexión que representó la victoria de Portugal frente a la selección canarinha por 3-1 en el Mundial de 1966; "el restablecimiento del orden" brasileño entre 1968-1989 y la recuperación del herido orgullo nacional portugués con la aparición de la "Generación de Oro" a partir de mediados de los años noventa.

En los capítulos 6 y 7 se analiza desde dos enfoques diferentes el fútbol femenino. La socióloga Cláudia Pinheiro nos presenta la evolución del fútbol femenino portugués y su gradual proceso de incorporación en los últimos años, pese a las innumerables resistencias a las que han tenido que hacer frente. En cambio, las brasileñas Cláudia Kessler y Silvana Goeller, sin salir del estudio del fútbol femenino o "futebol de mulheres" como ellas mismas quieren diferenciar, analizan la precaria situación del fútbol practicado por mujeres en Brasil.

Uno de los elementos más relevantes de este libro es su apuesta por el desarrollo de un estudio comparado entre ambos países partiendo del fútbol como elemento catalizador. Es indudable que las múltiples dimensiones que ofrece una investigación de este tipo es difícil abarcarlas en una única obra, pero al mismo tiempo, es de justicia destacar que este

Movimento, Porto Alegre, v. 20, n. 3, p. 1243-1251, jul./set. de 2014. 
trabajo permitirá asentar este ámbito de análisis e impulsar el desarrollo de futuros estudios que puedan ampliar los elementos que por limitaciones de espacio no han podido tratarse en este texto. Las investigaciones de la historia comparada del deporte son imprescindibles para poder avanzar en el conocimiento de los factores comunes de asimilación de fútbol en diferentes sociedades, sus respectivas influencias y rechazos, la construcción de identidades a través del deporte, o su utilización política, diplomática y propagandística. Es necesario que se desarrollen nuevos proyectos de investigación que avancen en el estudio de las relaciones entre Europa y Sudamérica, y principalmente respecto al análisis en profundidad de la histórica relación futbolística entre los países europeos de la cuenca mediterránea (Portugal, España e Italia) y Brasil, Argentina o Uruguay, superando los habituales estudios locales y nacionales.

El desafío de un análisis comparado se aprecia con un resultado satisfactorio en el texto de Maurício Drumond (capítulo 8), en el que se disecciona cómo Getúlio Vargas y Oliveira Salazar entendieron y utilizaron en sus respectivos países el fútbol como herramienta de propaganda, las diferencias y similitudes que existen entre los dos casos, así como el impacto que tuvieron dichas estrategias en relación con la utilización de otros métodos propagandísticos. La Copa Intercontinental de 1962 y el enfrentamiento entre el Santos de Pelé y el Benfica de Eusebio se convirtió en el símbolo futbolístico más potente de la rivalidad entre ambos países. Tanto el periodista portugués António Simões (capítulo 9), como el historiador brasileño Hilário Franco Junior (capítulo 10), analizan desde una perspectiva política, social y económica el impacto de los dos encuentros. El reportaje que Carlos Pinhão, uno de los grandes nombres del periodismo portugués, publicó en el periódico A Bola el 21

Movimento, Porto Alegre, v. 20, n. 3, p. 1243-1251, jul./set. de 2014. 
de julio de 1966 sobre el partido Portugal-Brasil en la fase de grupos del Campeonato del Mundo de 1966, se incluye en el capítulo 11 junto con los comentarios y aportaciones del académico Jorge Olímpio Bento y Leonor Pinhão (hija de Carlos Pinhão). También tiene su espacio en este texto el universo literario de uno de los mayores escritores de Brasil, Nelson Rodrigues, gracias a la acertada reflexión que realiza de sus escritos sobre la derrota brasileña en el Mundial de 1966 José Carlos Marques (capítulo 12).

Otro enfrentamiento histórico que ha quedado en la memoria futbolística de ambas sociedades, fue la final del Mundialito de 1972 que se disputó en Brasil y que venció esta última por 1-0. El periodista portugués Mário Zambujal, enviado especial para Record durante toda la competición recupera la crónica que publicó de la final con comentarios que ha incorporado cuarenta años después de esta cita histórica (capítulo 13). Filosofía y poesía también se dan la mano con João Tiago Lima y Luís Maffei, teniendo como elemento de debate los vínculos afectivos que unen a la Associação Académica de Coimbra y el Vasco da Gama, plasmados en el viaje que en 1971 realizaron los "estudiantes" a Brasil y que ambos analizan en un brillante dialogo futbolístico (capítulo 14).

Mención aparte merece el estudio comparativo que Victor Andrade de Melo realiza sobre cómo el cine representó al fútbol en ambos países. El autor, referencia internacional en este ámbito de la historia del deporte, nos presenta las estrechas relaciones que han existido entre las dos principales actividades de ocio de masas del siglo XX (capítulo 15). Por el contrario, el análisis técnico y táctico que realiza Luis Freitas del fútbol portugués y brasileño durante la segunda mitad del siglo XX, pese a su indudable demostración de conocimiento, 
deja al lector con el desencanto de un análisis más profundo y extenso.

La retrospectiva histórica y sociológica del fenómeno de la violencia en el fútbol que realizan Mauricio Murad y Daniel Seabra en los capítulos 17 y 18 respectivamente, también ha pretendido enfrentar al lector a la comparación entre el origen y evolución de un fenómeno que afecta dramáticamente al futbol en nuestros días. Murad analiza la situación actual de la violencia en los estadios brasileños relacionándola con el contexto social que vive el país, tratando de buscar elementos que permitan, de cara a los próximos mega eventos que en el futuro acogerá Brasil, afrontar en el corto, medio y largo plazo la reducción de estos comportamientos. Siendo consciente de los límites de estos grandes eventos deportivos, el propio autor considera que pueden servir como catalizadores que permitan paliar y ayudar mucho en la solución de estos problemas sociales: "Nenhum evento cultural será a panaceia de nossa dívida social, de nossas desigualdades seculares, estructurais e históricas, mas poderá ajudar e muito" (MURAD, 2013, p. 323). Seabra, por el contrario, trata de desmontar un lugar común en el fútbol portugués que identifica los años setenta con el inicio de la violencia en el fútbol. El análisis histórico de la prensa deportiva le permite identificar un contexto en el que se demuestra que desde el primer cuarto del siglo XX fueron múltiples los casos de violencia dentro y fuera del terreno de juego.

En el capítulo 19 Carlos Nolasco subraya que "Las migrações internacionais não são un fenómeno novo", pero es indudable que el actual contexto de globalización ha afectado a los flujos migratorios que generan el deporte en general y muy en especial el fútbol (2013, p.358). El éxito de los cinco mundiales ganados por Brasil y las cualidades técnicas de sus

Movimento, Porto Alegre, v. 20, n. 3, p. 1243-1251, jul./set. de 2014. 
futbolistas, han favorecido una fuerte corriente de emigración que ha tenido a Portugal como uno de sus principales países de destino en Europa. Por el contrario, han sido muy pocos los futbolistas que han elegido atravesar el Atlántico para triunfar en tierras brasileñas. Los brasileños Antônio Jorge Soares y Leonardo Bernardes Silva de Melo, analizan a continuación (capítulo 20) el mismo fenómeno pero dando voz a los propios futbolistas y descubriendo los principales rasgos de su perfil social y cultural. El libro concluye con la magnífica aportación (capitulo 22) del periodista Afonso de Melo, y su pormenorizado análisis de los momentos más relevantes de la que se ha conocido como "era Scolari", o el periodo desde finales de 2002 hasta el término de la Eurocopa de 2008 en el que Luiz Felipe Scolari dirigió a la selección portuguesa; y con el diccionario de Simone Nejaim Ribeiro de Bulhões (capítulo 23), reconocido especialista en Lengua Portuguesa que presenta un estudio comparado de los términos futbolísticos utilizados a cada lado del océano.

En A bola ao ritmo de fado e samba el fútbol se convierte en el elemento que facilita una novedosa aproximación al conocimiento de la cultura brasileña y portuguesa, permitiendo descubrir sus interrelaciones con la realidad económica, política e identitaria de ambos países. Entiendo que esta obra permite profundizar en un ámbito de la historia del deporte poco estudiado hasta el momento, ofreciendo elementos importantes para el debate y suscitando cuestiones pertinentes para poder avanzar en el conocimiento de la historia de las relaciones luso-brasileña a través del fútbol. 


\begin{abstract}
A bola ao ritmo de fado e samba: 100 anos de relações lusobrasileiras no futebol 1913-2013

Abstract: Abstract: This book review analyzes "A bola ao ritmo de fado e samba: 100 anos de relações luso-brasileiras no futebol 1913-2013", edited by sport historians Francisco Pinheiro and Victor Andrade de Melo. The book is a collection of papers by 25 authors who analyze the centenary of Luso-Brazilian relations from multiple perspectives - through football and the evolution of a century-long relationship. Furthermore, the book provides a dense and detailed narrative approach, adding analytical depth and revealing new aspects of the football-based relation between the two countries.

Keywords: Football. Brazil. Portugal. Book reviews.
\end{abstract}

A bola ao ritmo de fado e samba: 100 anos de relações luso-
brasileiras no futebol 1913-2013
Resumen: La reseña se refiere al libro "A bola ao ritmo de fado
e samba: 100 anos de relações luso-brasileiras no futebol 1913-
2013 ", coordinado por los historiadores del deporte Francisco
Pinheiro y Victor Andrade de Melo. Este libro es una compilación
de textos de 25 autores que analizan desde múltiples perspectivas
el centenario de las relaciones luso-brasileñas a través del fútbol,
así como la evolución de esta relación centenaria. Además, la
obra ofrece un enfoque narrativo denso y detallado, añadiendo
profundidad analítica y revelando nuevos aspectos de la relación
futbolística entre ambos países.
Palabras-clave: Fútbol. Brasil. Portugal. Reseña de libros.

\title{
REFERÊNCIA
}

PINHEIRO, F.; MELO, V. A. de (Coord.) A bola ao ritmo de fado e samba: 100 anos de relações luso-brasileiras no futebol 1913-2013. Porto: Edições Afrontamento, 2013.

Dirección postal del autor

Paseo de Yeserías $9,3^{\circ}$, CP 28005 ,

Madrid, España.

Recebido em: 05.11.2013

Aprovado em: 14.05.2014

Movimento, Porto Alegre, v. 20, n. 3, p. 1243-1251, jul./set. de 2014. 